\title{
Dificuldades enfrentadas por Professores de Ciências para ensinar Física no Ensino Fundamental
}

Marcos Gervânio de Azevedo Melo

Joanise Silva Campos

Wanderlan dos Santos Almeida

\section{Resumo}

O objetivo deste estudo é verificar que obstáculos estão presentes no ensino de Física realizado por professores de ciências das escolas municipais que trabalham com alunos do ultimo ano do ensino fundamental na cidade de Alenquer localizada no oeste do Pará. Foi realizada uma entrevista com os professores de Ciências que trabalham com as turmas do 9o ano nas escolas do município. Observou-se que dos cinco professores entrevistados trabalhando em escolas do município de Alenquer e que lecionam Física no último ano do ensino fundamental, nenhum possui formação em Física. Verificou-se também que os professores trabalham priorizando conteúdos de mecânica. Percebeu-se que um ponto que certamente contribui para uma repulsa à disciplina de Física, por parte dos alunos, é a cultura intensificada quase sempre por professores que acreditam piamente que as aulas práticas devam ocorrer em laboratórios sofisticados e que a falta dos mesmos inviabiliza os procedimentos práticos na escola.

Palavras-chave: Professores de Ciências; Obstáculos; Ensino de Física.

\section{Abstract \\ Difficulties faced by Teachers of Sciences to teach Physics in the Fundamental Teaching}

The objective of this study is to verify that obstacles are present in Physics teaching accomplished by teachers of sciences of the municipal schools that work with students of the last year of the fundamental teaching in the city of Alenquer located in the west of Pará. An interview was accomplished with the teachers of Sciences that work with the 9th year-old groups in the schools of the municipal district. It was observed that of the five interviewed teachers working at schools of the municipal district of Alenquer and that they teach Physics in the last year of the fundamental teaching, none possesses formation in Physics. It was also verified that the teachers work prioritizing mechanics contents. It was noticed that a point that certainly contributes for a repulse to Physics discipline, on the part of the students, it is the culture almost always intensified by teachers that believe sincerely that the practical classes should happen at sophisticated laboratories and that the lack of the same ones makes unfeasible the practical procedures in the school.

Keywords: Teachers of Sciences; Obstacles; Physics Teaching. 


\section{Introdução}

Como o Brasil forma um número pequeno de professores de Física em comparação aos docentes graduados em Biologia, Química e Matemática, o ensino fundamental acaba proporcionando o primeiro contato da disciplina de Física para os alunos diante, quase sempre, dos licenciados em outras áreas.

Basta adentrar as escolas, para observar biólogos, químicos, matemáticos, geólogos, meteorologistas, entre outros, ministrando aulas de Física. Isso ocorre principalmente na $8^{a}$ série, 9o ano, onde na maioria das escolas, inicia-se o contato formal com a disciplina em questão. Diante disto, várias questões podem ser refletidas, inclusive, aquelas relacionadas à motivação do próprio professor, pois sendo este de outra área, é natural que ele a priorize. Assim, é interessante entender este contexto na cidade de Alenquer-PA para se ter uma dimensão de como a Física está sendo introduzida formalmente aos alunos das escolas municipais deste município.

Dessa forma, a questão a ser respondida na pesquisa é a seguinte: como está sendo conduzido o ensino de Física, em nível fundamental, na opinião dos professores de ciências das escolas municipais da cidade de Alenquer no estado do Pará?

O objetivo geral deste estudo é verificar que obstáculos estão presentes no ensino de Física realizado por professores de ciências das escolas municipais de Alenquer que trabalham com alunos do ultimo ano do ensino fundamental.

Especificamente, esta pesquisa pretende:

Realizar um levantamento das escolas municipais que trabalham até o ultimo ano do ensino fundamental II, na cidade de Alenquer-PA; Verificar se os professores de ciências destas escolas trabalham assuntos de Física que devem ser introduzidos no 9o ano; Investigar que dificuldades estão presentes na opinião de professores de ciências que ensinam Física no 9o ano.

Assim, é importante refletir sobre o ensino de Física no Brasil, como este é mencionado na literatura e, principalmente, nos documentos oficiais que norteiam a Educação em nosso país.

\section{Refletindo o Ensino de Física no Brasil}

Para abordarmos o ensino da Física no Brasil devemos primeiro fazer uma reflexão acerca dos primórdios da universidade no país, que para muitos estudiosos surge somente a partir do século XIX. Antes disso, porém, durante o período monárquico, não interessava para Portugal introduzir iniciativas educacionais na colônia, muito menos instituições de ensino superior. Com a chegada dos portugueses vieram também os padres Jesuítas com a chamada Companhia de Jesus no Brasil, que tinha o papel de converter e catequizar os nativos com os ensinamentos de noções 
básicas de língua portuguesa e história cristã. "As primeiras Instituições de ensino superior foram criadas apenas em 1808 e as primeiras universidades são ainda mais recentes, datando de década de 1930" (DURHAM, 2005: p. 201).

Em 1910, surge a Academia Real Militar, que mais tarde transforma-se em Escola Nacional de Engenharia da Universidade Federal do Rio de Janeiro e em 1927 foram criadas duas faculdades de Direito, uma em São Paulo e outra em Olinda. A partir da Proclamação da República e da promulgação da Constituição Federal, surge no Brasil novas instituições de ensino, tanto de caráter público quanto privado. Este marco histórico para a então República Federativa do Brasil, fez com que a educação do país crescesse de maneira significativa e de 1889 a 1918 foram criadas mais de 50 escolas de nível superior. A partir da década de 1920, com a passagem de uma sociedade oligárquica para urbano industrial, foram redefinidas não só as estruturas econômicas, mas também os ideais por uma reforma no ensino nos mais diferentes níveis (Ibidem).

Paulatinamente, durante a Segunda República, o sistema de ensino superior continuou crescendo até 1960 onde podemos citar como marcos educacionais: a criação da Pontifícia Universidade Católica do Rio de Janeiro, a expansão do sistema universitário estadual paulista e o surgimento de instituições estaduais e municipais de ensino de menor porte em todas as regiões do país. É nesse período que surge a preocupação com ensino de Física, primeiramente nos Estados Unidos e em seguida na América Latina e por sua vez no Brasil através do projeto Physical Science Study Committee, o PSSC. Tal iniciativa surge a partir do entusiasmo e do grande desenvolvimento do ensino da ciência, em especial à Física, e tinha por objetivo maior inserir os jovens à carreira cientifica. Antes, porém, o ensino da Física no Brasil era pouco difundido, não se tinha, grosso modo, uma preocupação com tal ciência, pois

"Devido ao forte enfoque humanístico, as disciplinas cientificas eram praticamente excluídas do currículo. Um dado sobre o ensino de Física do império é que, mesmo o Colégio Pedro II sendo criado para ser uma referencia educacional à sua época, acabou sofrendo a forte influência do caráter humanístico. Apesar de possuir um currículo francês, baseado nas principais inovações cientificas, poucas inscrições eram realizadas nas disciplinas de física. (JÚNIOR; MATTOS, 2007)".

Vale lembrar que os livros didáticos utilizados durante o século XIX eram em sua maioria europeus, sobretudo franceses e resumiam-se em simples descrições de conceitos. Somente a partir do século XX foram incorporados livros didáticos de outras nacionalidades, como norteamericanos, visto que se destacavam por seus conteúdos algebrizados e uma abordagem demonstrativa experimental. Assim, nos anos 60 e 70, cabia a um aluno, no âmbito da Física, resolver problemas matemáticos, pois nesse período não havia espaço para se refletir os fenômenos físicos, mas apenas repetir de forma mecânica conhecimentos adquiridos. Não havia 
se quer espaço para se questionar o professor, pois esse detinha todo o conhecimento cientifico e o aluno era um mero expectador do conhecimento estabelecido (D’AMBRÓSIO, 1994). Tal prática acerca da Física rotulou-a como uma disciplina meramente mecânica, com os fins simplesmente nas resoluções de expressões matemáticas e que nada refletiam no conceito propriamente dito. Sabe-se, infelizmente, que tal fato deixou profundas marcas que ainda hoje refletem negativamente no ensino da Física. Quanto a isso, é importante ressaltar que

$$
\begin{aligned}
& \text { "[...] as competências maiores de um aluno no campo da Física estavam } \\
& \text { relacionadas à resolução de problemas numéricos em que a dificuldade não } \\
& \text { estava centrada no conceito Físico e, sim, nas relações matemáticas exigidas, } \\
& \text { nas operaçães efetuadas e na criatividade em desenvolver expressões } \\
& \text { algébricas para atingir resultados. Estas competências, ao serem } \\
& \text { desenvolvidas, propiciavam a criação de uma mentalidade pragmática em } \\
& \text { relação à Ciência [...] Além disso, a simples manipulação de equações sem o } \\
& \text { questionar/dialogar com a teoria Física associada não abre espaço para } \\
& \text { discussões mais elaboradas, não oportuniza o exercício da argumentação. Pelo } \\
& \text { contrário, em nome de uma suposta essencialidade de se aprender certas } \\
& \text { coisas, que na maioria servem apenas para brutalizar o aluno e, se possível, } \\
& \text { imbecilizar o futuro adulto, não abrem espaço para o essencial na educação } \\
& \text { (D’AMBRósıo, 1994, p.14)". }
\end{aligned}
$$

Diante do legado negativo desta prática docente, é importando salientar, que coube não só ao professor de Física, mas a todo o corpo que compõe a instituição escolar e principalmente ao órgão maior que rege e regulamenta a educação nacional - MEC - Ministério da Educação e Cultura, repensar novas práticas e objetivos acerca do ensino da física, a fim de buscar novos horizontes e implementar uma abordagem reflexiva e significativa para o aluno no que se refere ao ensino desta disciplina.

\section{Documentos Oficiais da Educação: Um Norte Para o Professor de Física no Brasil}

Como bem vimos, ao final do século XX a educação passava por uma reforma graças à luta e ao empenho de muitos educadores brasileiros, mas certamente um grande marco nessa reforma, foi a aprovação da Lei de Diretrizes e Bases da Educação Nacional - LDBEN - em 1996, LEI 9394/96. Essa Lei chega impulsionando o ensino médio, dando-lhe um novo norte e com objetivos bem claros que não lembram nem de longe o ensino praticado no período militar. Ela traz ainda uma inovação que são os Parâmetros Curriculares Nacionais que servirão de referencia às escolas, bem como aos professores. O ensino de Física no Brasil que ainda continua sendo um desafio para os professores que almejam encontrar técnicas que venham ajudar e auxiliar no 
desenvolvimento dessa disciplina de modo que os alunos se interessem pela mesma e sintam-se desafiados a aprender o conteúdo trabalhado, ganha um importante aliado que são os PCNEM. Para tanto, os PCNEM de Física trazem não técnicas, mas orientações para se trabalhar esse novo currículo referente à disciplina. Com isso, eles apontam competências que foram divididas em três blocos que diferenciam substancialmente dos objetivos do ensino de Física vistos nos anos 60 e 70 (BRASIL, 1999). Nesse sentido, vale lembrar que

"Um ensino por competências representa, dentro da nova legislação, uma possibilidade de superação do ensino de Física atualmente desenvolvido nas escolas. Ou seja, quer libertar-se e transcender do ensino tradicional, recheado por conceitos, leis e fórmulas tratados de forma desarticulada em relação ao mundo vivido pelo aluno e pelo professor, com insistência na automatização em resolução de exercícios e na memorização. O que o documento aponta é para uma Física que contribua para a constituição de uma cultura científica no aluno, que Ihe possibilite a compreensão de fatos e fenômenos naturais e a relação dinâmica do homem com a natureza. (RICARDO, 2005, p.31)“

Assim, a partir de todo esse apanhado histórico junto ao estudo da Física no Brasil, desde o inicio das escolas no país até os dias de hoje, temos, como professores de Física, e em posse dos PCN's, não a solução de todos os problemas referentes a essa disciplina, mas sim um desafio que fora lançado e que compete a cada docente trabalhar engajado e firme nesta proposta. Para tanto, é de extrema importância refletir a formação deste educador.

\section{Formação de Professores de Física no Brasil}

Como se pode perceber com a história da Física no Brasil, essa disciplina, diversas vezes, foi tratada com descaso ou trabalhada de maneira equivocada em nossos educandários e universidades. Claro que se deve lembrar que tal descaso não é privilégio apenas deste ramo de conhecimento.

Nesse contexto, é notória a necessidade de se formar mais professores de exatas e mais especificamente de Física para atuarem no sistema educacional do país. Contudo, mais que formar professores é necessário se formar bons professores e pesquisadores nessa área. Atualmente observam-se muitas escolas e alunos sofrendo com a falta desse profissional. Não é difícil verificar também que isso se dá pelo fato da falta de valorização, principalmente financeira, dos profissionais de educação.

Outro problema, no que se refere ao ensino de Física, aparece com relação ao pensar cientifico, tanto por parte de professores quanto de alunos. Essa dificuldade reflete diretamente no método, no aprendizado e por sua vez nos resultados. É fácil observar que essa atitude por 
parte dos professores é proveniente do próprio método educacional que tais profissionais também foram submetidos.

"No Brasil temos muito poucos dados empíricos confiáveis para afirmar qualquer coisa sobre os conhecimentos dos professores de Física, seja sobre o domínio que tem dos conteúdos e processos da Física, seja dos conteúdos e processos educacionais. [...] No entanto creio ser mais ou menos consensual que professores de Física recém-formados têm um domínio limitado da Física e dos processos científicos empregados na Física (BORGES, [201-?])."

Todas essas dificuldades são reflexos do que Borges chama de uma "crise no modelo de formação educacional" (Ibidem, [201-?]). Portanto, é certo afirmar que a formação dos professores de física precisa ser repensada e reformulada, mas necessita também ser constantemente investigada.

Logo, faz-se necessário entender a metodologia de pesquisa utilizada no estudo sobre professores de ciências que lecionam tal disciplina em Alenquer-Pa, cuja população está estimada em 54.353 habitantes segundo dados do Instituto Brasileiro de Geografia e Estatística - IBGE, verificados em Dezembro de 2014.

\section{Procedimentos Metodológicos}

Inicialmente, os pesquisadores realizaram uma busca por autores que discorrem na área de ensino de Ciências, bem como, em documentos oficiais relacionados à Educação.

Em seguida foi realizada, uma investigação junto a Secretaria Municipal de Educação relativa às escolas de ensino fundamental II, no sentido de saber quantas instituições trabalham até o 9o ano na cidade em questão.

Posteriormente, foi realizada uma entrevista com os professores de Ciências que trabalham com as turmas do 9o ano nas escolas do município. As entrevistas foram transcritas e categorizadas para uma posterior análise das mesmas. Os resultados analisados em conformidade com autores da área de ensino de ciências, bem como em relação aos documentos oficiais da educação, estão apresentados em tabelas e depoimentos.

\section{Resultados}

Inicialmente, pôde-se constatar, junto à SEMED de Alenquer, que somente 5 escolas municipais trabalham até o 9o ano neste município do estado do Pará, mas que na área urbana existem 18 instituições de ensino fundamental I e II. No entanto, a Secretaria Municipal informou 
que a maioria das escolas municipais está na zona rural do município, mas não precisou essa quantidade.

As entrevistas realizadas com os professores de Ciências do 90 ano das referidas escolas foram categorizadas e estão socializadas em tabelas. A Tabela 1, por exemplo, esboça a formação destes docentes, bem como, o tempo de serviço que cada um tem no magistério.

Tabela 1- Descrição profissional do professor

Formação

Ciências Naturais com habilitação em biologia

Matemática com especialização em matemática

Matemática com especialização no ensino de matemática

Ciências naturais e pedagogia

Língua portuguesa e cursando biologia e química
Professor Tempo de Trabalho

$\begin{array}{ll}\text { A } & 15 \text { anos } \\ \text { B } & 03 \text { anos } \\ \text { C } & 08 \text { anos } \\ \text { D } & 15 \text { anos } \\ \text { E } & 03 \text { anos }\end{array}$

É possível observar na Tabela 1 que dos cinco professores entrevistados trabalhando em escolas do município de Alenquer e que lecionam Física no último ano do ensino fundamental, nenhum possui formação em Física. Tal fato pode ser encarado como um indicador dos problemas que o discente enfrenta ao iniciar o ensino médio.

Apesar de percebemos que tem profissional atuando a mais de quinze anos nas salas de aula, apenas dois possuem especialização. No entanto, é possível verificar que a pós-graduação apresentada pelo docente não é em Física, mas em Matemática.

Além desta observação, é importante salientar que os professores apontam para alguns empecilhos que conduzem as suas práticas docentes. A Tabela 2 apresenta um demonstrativo disto.

Tabela 2 - Dificuldades dos professores para ministrar aulas

Dificuldades

Falta de Laboratório

Falta de domínio de conteúdo

Falta de internet

Falta de adequação ao conteúdo
Professores

$A, B, C$

$\mathrm{B}$

C

D

A Tabela 2 apresenta um obstáculo que caracteriza a grande maioria das escolas presentes no interior dos estados brasileiros, a falta de laboratório que é apontada por três professores, totalizando $60 \%$ dos entrevistados, é uma das dificuldades enfrentadas no ensino de Física.

É importante observar também que dois docentes mencionaram dificuldades relacionadas ao conteúdo, destacando-se o professor B que ressalta falta de domínio para se trabalhar com Física, pois o mesmo tem formação em Matemática.

R. B. E. C. T., vol 8, núm. 4, set-dez.2015 ISSN - 1982-873X

DOI: Em andamento. 
Ainda neste contexto, indagou-se sobre que conteúdos de Física estariam sendo trabalhados com os alunos do 9o ano. Os educadores relataram sistematizando de acordo com a Tabela 3.

Tabela 3 - Conteúdos trabalhados pelos professores

\section{Conteúdos}

Movimento, força, trabalho, potência energia e calor.

Trabalho

Velocidade média

Grandezas físicas e lei de Newton

Mecânica

\section{Professores}

A

C

$\mathrm{D}$

E

B

$\mathrm{Na}$ tabela 3 podemos observar que os professores trabalham priorizando conteúdos de mecânica, pois o tempo que é destinado para o conteúdo de Física corresponde a um semestre, o último do 9a ano do ensino fundamental. Tal fato pode ser percebido na fala de um docente:

"Olha rapaz, essa proposta curricular de ensino voltada para o ga ano do ensino fundamental [...] o pessoal da secretaria dispõe o conteúdo de Física só nos últimos bimestres do ano letivo' (Professor E, 12/05/2014)."

O depoimento do professor reflete uma imagem que já fora percebida na Tabela 1, pois como não aparece na citada tabela nenhum professor formado em Física, acaba-se priorizando o conteúdo das outras disciplinas em detrimento da Física que fica deslocada para o final deste trabalho do ensino fundamental.

\section{Análise dos Resultados}

Não é difícil perceber que o ensino de Física apresenta problemas e que a formação dos professores em áreas adjacentes, como Matemática, por exemplo, evidenciada na Tabela 1, não é suficiente para atender as necessidades dos educandos. Tal problemática é apontada por Silva et al. $(2002$, p.243) ao mencionar que:

"É muito nítido que, em muitas instituições de ensino no Brasil, os professores encarregados de conduzir o processo de ensino em Ciências no ensino fundamental têm formação em Biologia, sem grande entusiasmo em relação ao ensino de Química ou Física."

Dessa forma, não se pode duvidar que os alunos percebam que o professor formado em Matemática, certamente, oferece maior resistência ao ensino de Física e que, assim, acabe por disponibilizar maior tempo de seu trabalho ao conteúdo da disciplina na qual se graduou. Esta observação discente pode contribuir para que o mesmo apresente aversão à disciplina de Física, 
pois o início do contato formal com este conteúdo já está caracterizado por uma inércia e isto pode ser observado em algumas falas como:

"[...] na escola de segundo grau, muitos alunos, provavelmente a maioria, preferem, em termos de ciências, a Biologia e a Química em relação à Física. [...] a Física é considerada uma matéria difícil, a qual muitos alunos evitariam se pudesse. Ao que parece, eles aprende muito cedo a não gostar de Física (MOREIRA, 1983, p.11)."

Outro ponto que certamente contribui para uma repulsa à disciplina de Física, por parte dos alunos, é a cultura intensificada quase sempre por professores que acreditam piamente que as aulas práticas devam ocorrer em laboratórios sofisticados e que a falta dos mesmos inviabiliza os procedimentos práticos na escola. Esta questão foi apontada como dificuldade encontrada por três dos cinco docentes entrevistados, mas pode ser refletida ao se lembrar que:

"É um equívoco corriqueiro confundir atividades práticas com a necessidade de um ambiente com equipamentos especiais para a realização de trabalhos experimentais, uma vez que podem ser desenvolvidas em qualquer sala de aula, sem a necessidade de instrumentos ou aparelhos sofisticados (BORGES, 2002, p.294)."

Dessa forma, o professor deve estar atento para as possibilidades de inserir os discentes em contextos experimentais, independente de a escola oferecer este espaço, pois a utilização de materiais de baixo custo e/ou de materiais recicláveis como garrafas PET, entre outros, pode ser uma alternativa interessante para a condução desta prática docente na disciplina de Física.

Finalmente, abri-se espaço para se refletir o conteúdo de Física trabalhado no 9 o ano nas cinco escolas alvo desta investigação. A Tabela 3 esboçou os mesmos, sendo possível observar uma prioridade ao conteúdo de mecânica. Os demais assuntos que compõem a grade curricular da disciplina de Física como ondas, termologia, óptica, eletricidade e física moderna, pouco, ou nada, aparecem nas falas dos docentes na referida tabela. Isso, de certa forma, acaba passando uma imagem da Física desvinculada da realidade, pois o cotidiano dos alunos apresenta um aparato tecnológico que parece ter muito pouco haver com esta Ciência. Os Parâmetros Curriculares Nacionais ressaltam que

"Para o ensino [...] meramente propedêutico atual, disciplinas científicas como a Física, têm omitido os desenvolvimentos realizados durante o século XX e tratam de maneira enciclopédica [...] os conteúdos tradicionais (BRASIL, 1999, p.209)."

Dessa forma, é possível observar que a formação dos professores acaba sendo decisiva na escolha de certos conteúdos trabalhados, pois a não formação em Física, especificamente, certamente conduziu os docentes a priorizar o trabalho com o conteúdo de mecânica.

R. B. E. C. T., vol 8, núm. 4, set-dez.2015 ISSN - 1982-873X

DOI: Em andamento. 


\section{Considerações Finais}

Um dos problemas que ficou evidente neste estudo, relativo ao ensino de Física no ensino fundamental, e que certamente merece a atenção, em especial, das autoridades gestoras da educação no citado município, mas que indubitavelmente reflete um problema no país, se refere à qualificação dos professores que lecionam a mencionada disciplina neste nível de ensino.

Fica claro que esta formação em áreas adjacentes proporciona uma insegurança para que os docentes trabalhem determinados conteúdos de Física e esta falta de confiança acaba fazendo com que os educadores trabalhem de maneira superficial, sem aspectos histórico-filosóficos e desvinculados da realidade.

Percebe-se, também que ao priorizar a disciplina a qual o docente tem formação, como Biologia, por exemplo, este não procura articular a citada disciplina com a Física nas séries anteriores ao 9 o ano deixando para trabalhar conteúdos de Física somente neste último momento do ensino fundamental. Isso reflete uma imagem de uma Ciência compartimentada com limites bem definidos.

A justificativa de falta de laboratórios como uma dificuldade ao trabalho na disciplina de Física também parece ser, muito mais, um indicativo relacionado ao conhecimento, ou a falta dele, que a carência de alternativas práticas para a tarefa na disciplina, pois o educador tem inúmeras possibilidades de proporcionar momentos experimentais ao aluno.

\section{Referências}

BORGES, A. Tarcisio. Novos Rumos para o Laboratório Escolar de Ciências. Caderno Brasileiro Ensino Física, v.19, n.3: p. 291-313, 2002.

BORGES, Oto. A formação inicial de professores de física: formar mais! Formar melhor!. [201-?] Disponível em: <http://www.scielo.br/scielo.php?pid=S180611172006000200003\&script=sci_arttext>. Acesso em: 01 ago. 2014.

BRASIL. Ministério da Educação (MEC), Secretaria de Educação Média e Tecnológica (Semtec). Parâmetros Curriculares Nacionais para o Ensino Médio, Brasília: MEC/Semtec, 1999.

D’AMBRÓSIO, U. Ciências, informática e sociedade: uma coletânea de textos. Brasília: 1994. DURHAM, E. Educação superior, pública e privada (1808- 2000). In: SCHWARTMAN,Simon \& BROCK,Colin. Os desafios da educação no Brasil. Rio de Janeiro. Nova Fronteira. 2005. p.197240.

IBGE. Informações estatísticas. Rio de Janeiro: IBGE, 2014. Disponível em: < http://www.cidades.ibge.gov.br/xtras/perfil.php?lang=\&codmun=150040\&search=para|alenq uer $>$. 
JUNIOR, Roberto Bovo Nicioli. MATTOS, Cristiano. História e memória do ensino de física no Brasil: a faculdade de medicina de São Paulo: 2007. Disponível em: <http://www.scielo.br/scielo.php?script=sci arttext\&pid=S1516-73132012000400008>.

Acesso em: 01 ago. 2014.

MOREIRA. Marco Antonio. Uma abordagem Cognitiva ao Ensino de Física: A Teoria da Aprendizagem significativa de David Ausubel como sistema de referência para organização do ensino de Ciências. Porto Alegre. Ed. Da UFRGS, 1983.

SILVA, R. C; COPETTE, M. C; SILVA, A; LIMA, R. P. de; SILVA, J. S. A; MACHADO, S. da S. L. Um higrômetro de vagem e a física no ensino fundamental. Caderno Brasileiro de Ensino de Física, Florianópolis, v. 19, n. 2, p. 242-252, ago. 2002.

RICARDO, E. C. Competências, interdisciplinaridade e contextualização: dos Parâmetros Curriculares Nacionais a uma compreensão para o ensino de ciências. Tese (Doutorado em Educação Científica e Tecnológica). UFSC: 2005.

Marcos Gervânio de Azevedo Melo. Professor Me de Física do Instituto de Ciências da Educação ICED da Universidade Federal do Oeste do Pará - UFOPA. marcosgervanio@bol.com.br Joanise Silva Campos. Licenciada em Física pelo Plano articulado de Formação de Professores PARFOR da Universidade Federal do Oeste do Pará - UFOPA e professora da rede municipal de Alenquer-PA. joelarinha@hotmail.com

Wanderlan dos Santos Almeida. Licenciado em Física pelo Plano articulado de Formação de Professores - PARFOR da Universidade Federal do Oeste do Pará - UFOPA e professor da rede municipal de Alenquer-PA.wanderlan almeida@yahoo.com.br 